\begin{tabular}{|cc|}
\hline ETHENE & PROPENE \\
BUTENES & PENTENES \\
GASOLINE & VAPOR \\
SAMPLING & ADSORBENTS \\
GAS SOLID CHROMATOGRAPHY \\
\hline
\end{tabular}

Open access reviewed manuscript version of Intern. J. Environ. Anal. Chem. 45 (1991) 39-44

\title{
Selective assessment of C2-C6 alkenes in air by adsorption sampling and gas chromatography
}

\author{
Lars Löfgren, Pia M. Berglund, Rolf Nordlinder, \\ Göran Petersson and Olle Ramnäs \\ Department of Chemical Environmental Science, Chalmers University of Technology, \\ S-41296 Göteborg (Sweden)
}

Subsequent analytical applications:

Butenes in urban air

$\underline{\text { Hydrocarbons from traffic }}$ 
SELECTIVE ASSESSMENT OF $\mathrm{C}_{2}-\mathrm{C}_{6}$ ALKENES IN AIR BY ADSORPTION SAMPLING AND GAS CHROMATOGRAPHY

Lars Löfgren, Pia M Berglund, Rolf Nordlinder, Göran Petersson and Olle Ramnäs

Department of Chemical Environmental Science

Chalmers University of Technology

S-412 96 Göteborg, Sweden

\section{ABSTRACT}

A system is described for the specific determination in air of ethene, propene, the four isomeric butenes, cyclopentene and the six isomeric pentenes. The butenes, pentenes and hexenes are well separated from the commonly occurring matrix of alkanes in much higher concentrations.

Field samples were taken using easily carried equipment consisting of an air pump connected to an adsorbent cartridge. An advantageous combination of triple-layer adsorbents was found to be Tenax + Carbotrap + Carbosieve S-III. In the laboratory, the hydrocarbons were thermally desorbed into a cold trap. The trap was directly linked to the aluminium oxide PLOT column which effected the alkene separations.

KEY WORDS: Ethene, Propene, Butenes, Pentenes, Auto exhaust, Petrol vapour 


\section{INTRODUCTION}

Alkenes in air are of great environmental importance because of their rapid, efficient contribution to the formation of ozone and other photo-oxidants ${ }^{1}$. They are also important with respect to urban health hazards owing to their metabolic conversion to genotoxic epoxides ${ }^{2}$.

The present study describes an analytical method for alkenes developed and modified through several years after a first, very preliminary report $^{3}$. Reported applications of the method include a study of petrol hydrocarbons from refuelling ${ }^{4}$ and a study of butenes from automobile exhaust in urban air 5 . The usefulnes of the $\mathrm{Al}_{2} \mathrm{O}_{3}$ column for the separation of alkenes has been demonsrated earlier ${ }^{6}$. Recently, air sampling of $\mathrm{C}_{2}-\mathrm{C}_{4}$ alkenes on different adsorption tubes has been evaluated 7 . Alternative systems for sampling and gas chromatographic assessment of hydrocarbons in air have been reviewed 8 . 


\section{EXPERIMENTAL}

\section{Sampling}

The adsorbent cartridges were carefully cleaned glass tubes (150 $\mathrm{mm} \times 4 \mathrm{~mm}$ i.d.) filled with three separate layers of adsorbents. These were Tenax TA ( $0.6 \mathrm{ml}, 60 / 80$ mesh, Chrompack) for the front layer, Carbotrap (0.4 ml, 20/40 mesh, Chrompack) or Ambersorb XE 340 for the intermediate layer and Carbosieve S-III ( $0.4 \mathrm{ml}, 60 / 80$ mesh, Chrompack) or Carbosphere (60/80 mesh, Alltech associates) for the rear layer. New cartridges were preconditioned before use at $230^{\circ} \mathrm{C}$ with a flow of pure helium over night.

A personal sampling pump was connected to the rear end of the cartridge with a Swagelok fitting. The sampling rate was below $50 \mathrm{ml} / \mathrm{min}$ and the accurately determined air volumes in the range from below $100 \mathrm{ml}$ up to 2 litres. Before and after sampling, the cartridges were kept in sealed glass tubes, placed in brown glass bottles during transport.

\section{Thermal desorption}

The sampling cartridge was placed in a thermal desorption oven and fitted into the carrier gas line with the Tenax end towards the gas chromatograph (Carlo Erba 2900). Desorption of the hydrocarbons was carried out at $200-230^{\circ} \mathrm{C}$ for $15 \mathrm{~min}$ with $20 \mathrm{ml} / \mathrm{min}$ of helium into a cold trap in the column oven. The trap was a coiled glass-lined metal tubing ( $400 \times 0.7 \mathrm{~mm}$ i.d.) filled with glass beads $(0.1-0.2 \mathrm{~mm})$ and 
placed in a small Dewar flask filled with liquid nitrogen $\left(-196^{\circ} \mathrm{C}\right)$. During desorption, helium was vented through a valve after passing through the trap. After the desorption period, this valve was closed and the liquid nitrogen was blown away from the trap by compressed air. Injection into the analytical column was accomplished by electrically heating the trap coil to $220^{\circ} \mathrm{C}$.

\section{Gas chromatography}

The key component in the analytical system was the aluminium oxide gas-solid chromatography column (porous-layer open tubular - PLOT, $50 \mathrm{~m} \times 0.32 \mathrm{~mm}$ i.d., Chrompack). The $\mathrm{Al}_{2} \mathrm{O}_{3}$ stationary phase was mixed with $5 \% \mathrm{KCl}$ to moderate its activity ${ }^{6}$. The carrier gas flow was about $3 \mathrm{ml} / \mathrm{min}$ of helium.

Detection was normally accomplished using FID, and chromatograms and chromatographic data were obtained from recording integrators. Optional specific detection using PID (HNU, 10.2 eV) aided in recognizing alkenes. Final identifications were made from retention data and comparisons with authentic hydrocarbons.

Standard gas mixtures

Response factors were determined for representative hydrocarbons from samples of standard gaseous diluted hydrocarbon mixtures. The hydrocarbons $(5-10 \mathrm{mg} \pm 0.01 \mathrm{mg})$ in sealed glass tubes were put into a 
gas cylinder $\left(2.5 \mathrm{dm}^{3}\right)$, which was filled with nitrogen $(250-500 \mathrm{~g}$ $\pm 0.1 \mathrm{~g}, 100-200 \mathrm{bar}$ ) and agitated to crush the glass tubes. From the precisely weighed amounts of hydrocarbons and nitrogen, the concentrations of the gas standard were obtained. Standards of lower concentrations were prepared by slowly releasing the pressure of the cylinder to atmospheric pressure and refilling it with nitrogen up to 100 - 200 bar. 
RESULTS AND DISCUSSION

Separation of alkenes

As illustrated by the chromatogram in Figure 1 , the $\mathrm{C}_{2}-\mathrm{C}_{6}$ alkenes are very favourably separated from the prominent alkanes on the aluminium oxide column. In addition, all of the four isomeric butenes and the six isomeric pentenes are well separated. The sample corresponding to Figure 1 has a high content of $\mathrm{C}_{4}-\mathrm{C}_{6}$ hydrocarbons from evaporated petrol and a much lower proportion of $\mathrm{C}_{2}-\mathrm{C}_{3}$ hydrocarbons from auto exhaust than average urban air.

Interactions between the double bond and the stationary phase explain why the alkenes appear after the corresponding alkanes. The $c i s$ isomers elute after the trans isomers because of their better accessibility for interaction. The normal appearance of branched hydrocarbons before non-branched ones is observed for the alkanes and for 3-methyl-1-butene. With alkenes, the effect of branching appears to be counteracted on the strongly polar $\mathrm{Al}_{2} \mathrm{O}_{3}$ phase by the electron-donating effect of an alkyl branch next to the double bond.

The applications given in Table 1 illustrate the composition of butenes and pentenes of petrol vapour. An extensive study of alkenes from refuelling has been published ${ }^{4}$. The composition of butenes in urban air differs from that given in Table 1 because of a contribution from combustion products in auto exhaust ${ }^{5}$. The favourable separation of 


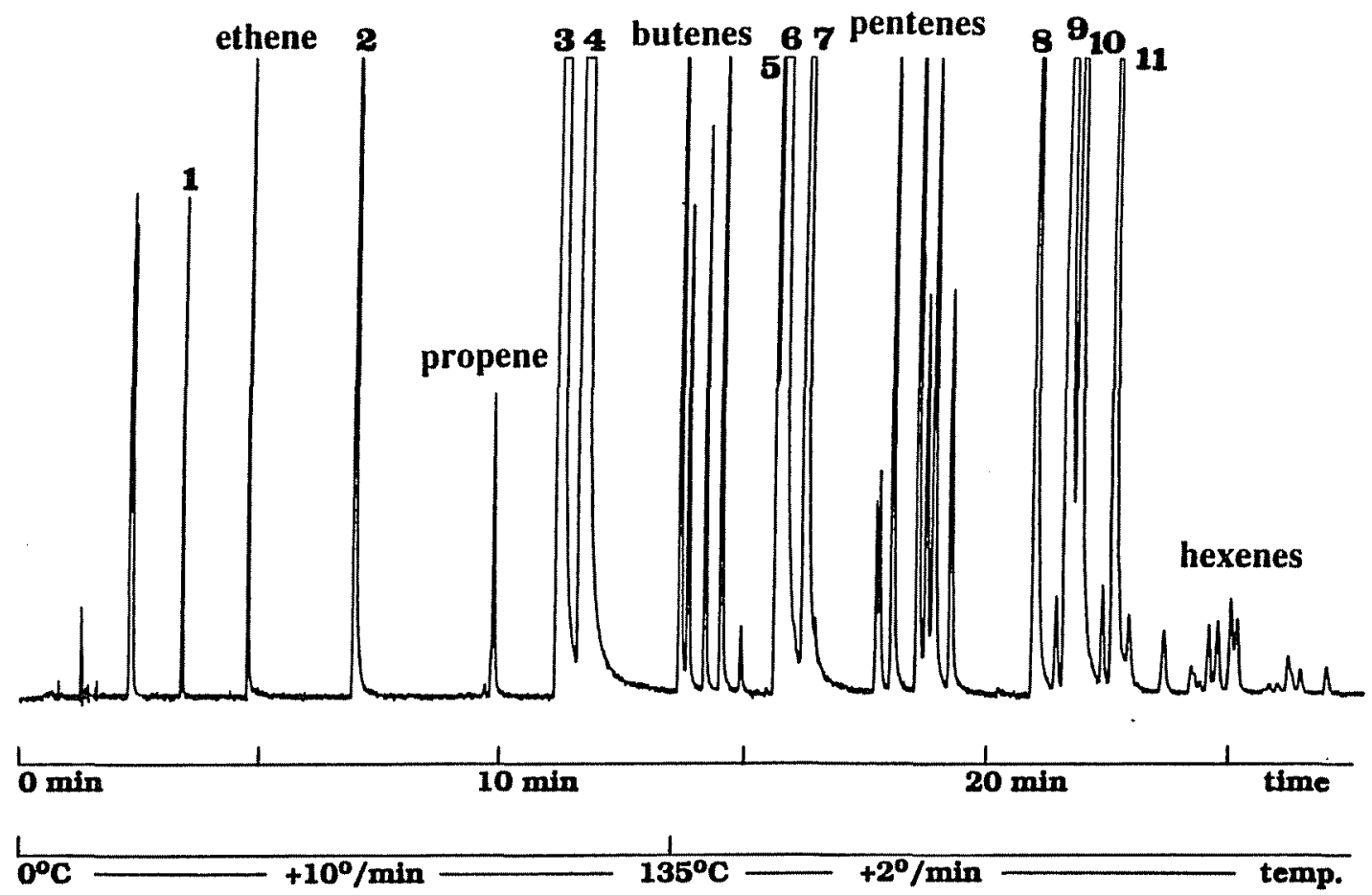

Figure 1. Separation of alkenes from other ambient hydrocarbons. Air sample taken at a service station near traffic in Göteborg, June 1988. Butenes in elution order: trans-2-butene, 1-butene, methylpropene, cis-2-butene. Pentenes in elution order: cyclopentene, 3-methyl-1-butene, trans-2-pentene, 2-methyl-2-butene, 1-pentene, 2-methyl-1-butene, cis-2-pentene.

Non-olefinic hydrocarbons: 1 ethane, 2 propane, 3 methylpropane, 4 -butane, 5 cyclopentane, 6 methylbutane, $7 n$-pentane, 8 methylcyclopentane, 9 2-methylpentane, 103 -methylpentane, 11 -hexane 
Table 1. Composition of alkenes $\left(\mu \mathrm{g} / \mathrm{m}^{3}\right)$ in air polluted by petrol vapours.

\begin{tabular}{lcclcc}
\hline Butenes & $\mathrm{a}$ & $\mathrm{b}$ & Pentenes & $\mathrm{a}$ & $\mathrm{b}$ \\
\hline trans-2-Butene & 3700 & 23 & Cyclopentene & 500 & 4 \\
1-Butene & 1600 & 9 & 3-Methyl-1-butene & 700 & 5 \\
Methylpropene & 1600 & 9 & trans-2-Pentene & 2500 & 21 \\
cis-2-Butene & 3000 & 15 & 2-Methyl-2-butene & 3100 & 24 \\
& & & 1-Pentene & 1400 & 11 \\
& & & 2-Methyl-1-butene & 2400 & 18 \\
& & & cis-2-Pentene & 1300 & 11 \\
& & & & &
\end{tabular}

a) Short-time sample (1.0 min), reflecting exposure during conventional refuelling of petrol.

b) The sample (20 min) corresponding to Figure 1, reflecting ambient air levels at a service station. 
butenes was early demonstrated in a description of the aluminium oxide column ${ }^{6}$. The advantageous separation ability has also been used in studies based on adsorption sampling?.

\section{Column performance}

If required, the temperature program followed in Figure 1 could be speeded up considerably without a great loss of resolution. The separation of incompletely resolved hydrocarbons could be improved by selecting specific temperature programs.

Polar compounds including halocarbons, aldehydes, ketones, esters and alcohols are retained very strongly or decomposed in the front end of the column. As a result, almost exclusively hydrocarbons appear on the chromatogram. In the study of alkenes, this may be an important advantage.

Water from the sampling cartridge affects particularly $\mathrm{C}_{6}$ and higher hydrocarbons, resulting in decreased retention and impaired separation. An optional $\mathrm{MgClO}_{4}$ filter in the carrier gas stream after the desorption oven removed water from the samples, but potential losses of late-eluting hydrocarbons had to be controlled for samples containing much water. Normally no losses of $\mathrm{C}_{2}-\mathrm{C}_{6}$ hydrocarbons were observed on the filter as indicated by duplicate samples analyzed without the filter.

To maintain the analytic quality of the column, it was often conditioned at its maximum recommended temperature $\left(205^{\circ} \mathrm{C}\right)$ overnight. The same 
column was used for several years and for thousands of samples without any significant deterioration in its performance.

\section{Adsorbents for sampling}

The well-known Tenax porous polymer was chosen as the front adsorbent because of its excellent adsorption and desorption properties for hydrocarbons $\geq \mathrm{C}_{6}$ at high sampling volumes $(>1000 \mathrm{ml})$ and for hydrocarbons $\geq \mathrm{C}_{4}$ at small sampling volumes $(<100 \mathrm{ml})$. As illustrated in Figure 2, using Carbosieve S-III as the rear adsorbent enabled quantitative sampling of all alkenes up to the $1000 \mathrm{ml}$ range. Breakthrough of ethene was normally observed only at large sampling volumes, but the limit was lowered by increasing temperature, air humidity and hydrocarbon concentrations. Ethene is less strongly adsorbed than propene. As a result, the characteristic ratio in urban air between ethene and propene (Figure 2) can often be used to confirm quantitative adsorption of ethene, thus eliminating the need for laborious break-through studies.

Tendencies to losses on the rear adsorbents increase with molecular weight for the $\mathrm{C}_{4}-\mathrm{C}_{5}$ alkenes if they penetrate the Tenax layer. Carbotrap was found to be a suitable intermediate adsorbent to prevent contact between reactive $\mathrm{C}_{4}$ and $\mathrm{C}_{5}$ alkenes and the active back-end adsorbent.

Among the pentenes, 2-methyl-2-butene was found to be particularly 


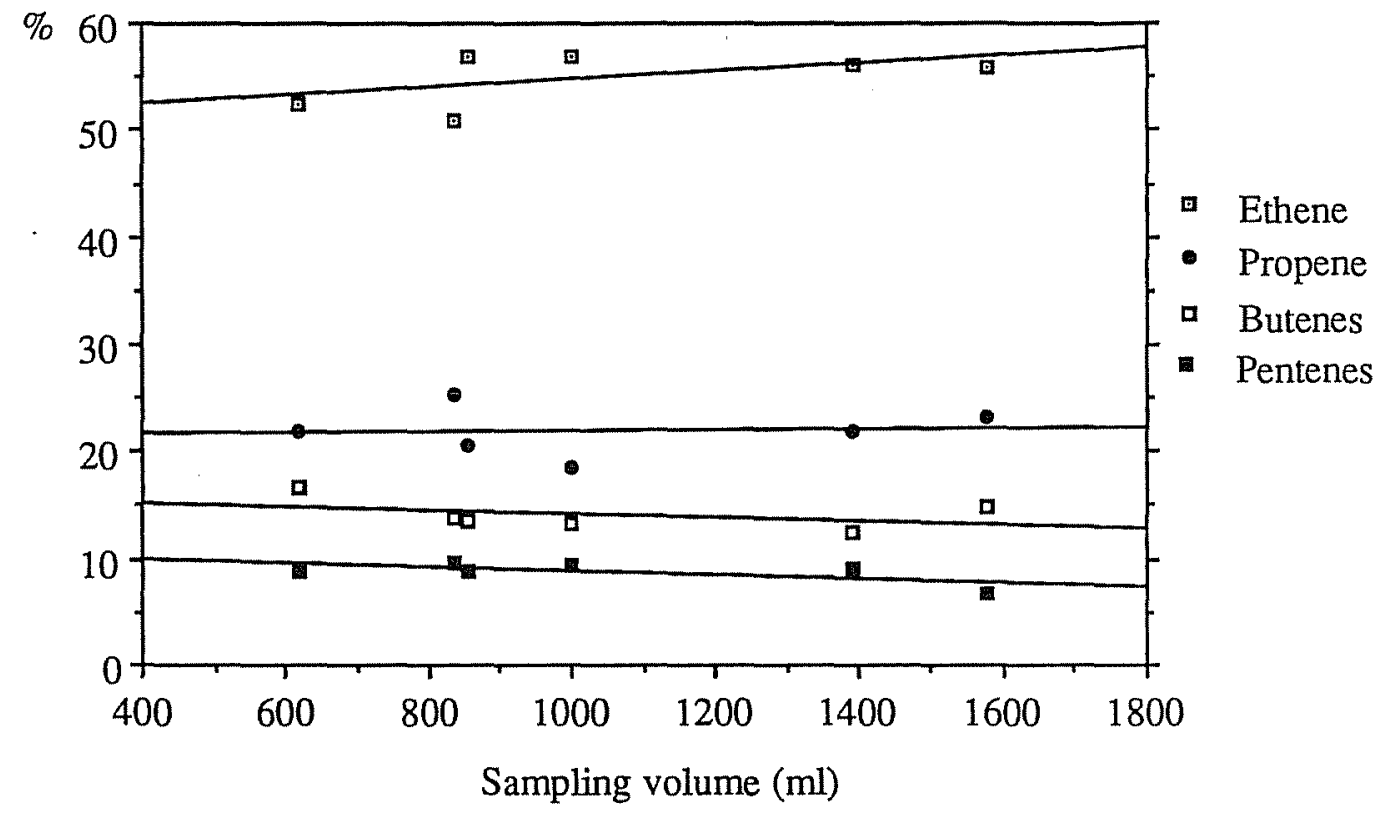

Figure 2. Percentual composition of alkenes in urban air polluted with traffic exhaust for samples taken in Göteborg 1989-1990. Adsorbents: Tenax TA + Carbotrap + Carbosieve S-III. 
sensitive to losses on active adsorbents. The concentration pattern for pentenes given in Table 1 illustrates their true composition in urban air polluted by petrol vapour or petrol exhaust. A different pattern with a lowered proportion of 2-methyl-2-butene was found to be the best indication of losses on the adsorbent cartridge.

The samples reported in Figure 1 and Table 1 refer to the adsorbent combination Tenax TA + Ambersorb XE-340 + Carbosphere, which was used for many years. At present, the combination Tenax TA + Carbotrap + Carbosieve S-III is preferred with respect to quantitative adsorption of ethene as well as quantitative desorption of pentenes. 


\section{References}

1. A. M. Hough and R. G. Derwent, Atmos. Environ. 21, 2015 (1987).

2. S. Osterman-Golkar and L. Ehrenberg, Drug Metab. Rev. 13, 647 (1982).

3. R. Nordlinder, O. Ramnäs and L. -E. Åmand, Chrompack News, 11:4 E (1984).

4. P. M. Berglund and G. Petersson, Sci. Total Environ. 91, 49 (1990).

5. L. Löfgren and G. Petersson, Sci. Total Environ. (in press, 1991).

6. J. De Zeeuw, R. C. M. De Nijs and L. T. Heinrich, J.Chromatogr. Sci. 25, 71 (1987).

7. S. E. Maljaars and M. W. F. Nielen, Intern. J. Environ. Anal. Chem. 34, 333 (1988).

8. H. -J. Schaeffer, HRC \& CC 12, 69 (1989).

9. M. Kanakidou, B. Bonsang and G. Lambert, Atmos. Environ. 23, 921 (1989). 